\title{
Deciphering the Role of the Barr Body in Malignancy An insight into head and neck cancer
}

"Deepti Sharma, ${ }^{1}$ George Koshy, ${ }^{1}$ Shruti Gupta, ${ }^{2}$ Bhushan Sharma, ${ }^{1}$ Sonal Grover ${ }^{1}$

$$
\text { فلك رموز دور الجسم بار في السرطان }
$$

ديبتي شارما، جورج كوشي، شرتي جويتا، بوشان شارما، سونال جروفر

\begin{abstract}
X}$ chromosome inactivation is the epitome of epigenetic regulation and long non-coding ribonucleic acid function. The differentiation status of cells has been ascribed to X chromosome activity, with two active X chromosomes generally only observed in undifferentiated or poorly differentiated cells. Recently, several studies have indicated that the reactivation of an inactive X chromosome or X chromosome multiplication correlates with the development of malignancy; however, this concept is still controversial. This review sought to shed light on the role of the $\mathrm{X}$ chromosome in cancer development. In particular, there is a need for further exploration of the expression patterns of X-linked genes in cancer cells, especially those in head and neck squamous cell carcinoma (HNSCC), in order to identify different prognostic subpopulations with distinct clinical implications. This article proposes a functional relationship between the loss of the Barr body and the disproportional expression of $\mathrm{X}$-linked genes in HNSCC development.
\end{abstract}

Keywords: Sex Chromatin; X Chromosome; Lyonization; X-Linked Genes; Cell Differentiation; Cancer; Squamous Cell Carcinoma, Head And Neck.

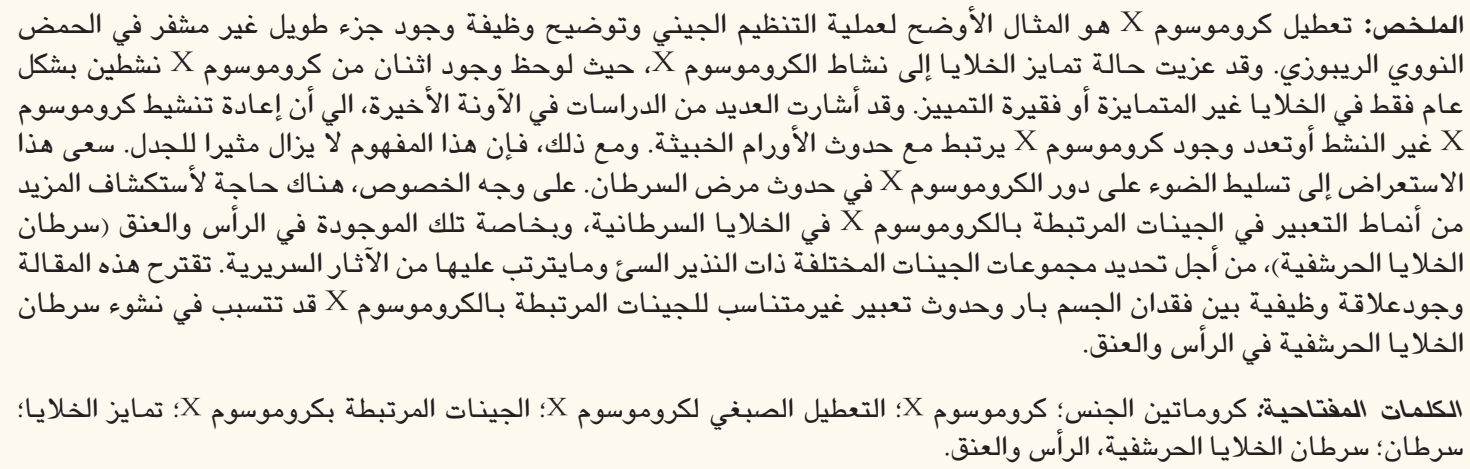

G ENETIC AND EPIGENETIC PROCESSES RESULT in heritable changes in the expression of cancer cells; consequently, the molecular targets of malignancy include critical tumour-associated genes-such as tumour suppressor genes (TSGs) or oncogenes-along with their mutations, amplifications, deletions, loss of heterozygosity or other epigenetic modifications. ${ }^{1}$ Recently, researchers have confirmed the role of DNA methylation and histone modification of the cytosine-guanine (CpG) site in malignancy as well as the interrelation between nuclear architecture, chromatin packaging, heterochromatin organisation, epigenome and noncoding ribonucleic acid (RNA). ${ }^{2}$ Many X-linked potential TSGs and oncogenes have been attributed to the distinctive biology of the $\mathrm{X}$ chromosome and its specific implications in malignancy. ${ }^{3}$ The exclusivity of TSGs to the $\mathrm{X}$ chromosome can be attributed to their inactivation by a single referred loss of function mutation (i.e. hit); in other words, if a tumour suppressor gene is localised on the $\mathrm{X}$ chromosome, one hit is sufficient to induce tumorigenesis because the other allele on the $\mathrm{X}$ chromosome is inactivated by epigenetic modification. Moreover, the reactivation of the inactive $\mathrm{X}$ chromosome (Xi) could ultimately lead to oncogene overexpression. ${ }^{4}$

In female somatic cells, an $\mathrm{Xi}$ is referred to as the Barr body. In malignant cells, the disappearance of the 
Barr body results in misregulation of the centromereassociated satellite heterochromatin and the peripheral heterochromatic compartment, potentially causing broad epigenetic instability. ${ }^{5}$ As such, the Barr body is considered an epigenetic nuclear landmark in cancer development. Recent interest in exploring the loss of the Barr body in different malignancies has been encouraged by the high frequency of this phenomenon in aggressive breast cancers. ${ }^{6}$ Nevertheless, the association between Barr body disappearance and genetic loss, epigenetic instability or transcriptional reactivation is still ambiguous. ${ }^{?}$

Head and neck squamous cell carcinoma (HNSCC) is the sixth most common cancer worldwide and has been associated with conventional aetiological factors including tobacco and alcohol consumption. ${ }^{8}$ However, the growing incidence of oropharyngeal squamous cell carcinoma in Western countries in the absence of a corresponding rise in smoking and alcohol consumption points towards the involvement of additional behavioural and environmental factors, such as human papilloma virus (HPV) infection and epigenetic instability. ${ }^{9}$ Strong evidence exists that altered DNA methylation profiles in HNSCC cases reflect the aberrant epigenetic regulation of TSGs and oncogenes. ${ }^{10}$ As such, it is imperative that researchers concentrate on epigenetic pathways because of their reversible nature when seeking new approaches to the molecular diagnosis and targeted treatment of cancer.

While X chromosome perturbations have been reported in breast, uterine, cervical, ovarian, renal and colon cancers, they are rarely documented in HNSCC cases. $^{7,11-14}$ This article focuses on reviewing variations in Barr body frequency in different malignancies and proposing its hypothetical involvement in HNSCC development. There is a need to further explore the role of sex chromosomes in HNSCC development in order to determine potential clinical implications.

\section{The Barr Body and X Inactivation}

During early embryonic development in females, the random inactivation of one of the two X chromosomes occurs and is maintained subsequently throughout further cell division. ${ }^{15}$ The term Barr body was first used to describe this transcriptionally inert, heterochromatic and late-replicating chromatin mass by Barr et al. in 1949. ${ }^{16}$ This inactivation of an X chromosome results in equivalent gene dosage (i.e. $\mathrm{XX}$ and $\mathrm{XY}$ ) between the sexes by the synchronised transcriptional silencing of genes; thus, both sexes have one copy of an active $\mathrm{X}$ chromosome (Xa), which is necessary for the embryo to survive. ${ }^{17}$
Critically, $\mathrm{X}$ inactivation represents numerous epigenetic mechanisms that result in the formation and maintenance of facultative heterochromatin in mammals. ${ }^{14}$ The $X$-inactive specific transcript (XIST) gene is the linchpin of $X$ inactivation, whereby heterochromatin silencing is mediated via XIST expression and stabilisation of its non-coding RNA transcript. ${ }^{18}$ The XIST gene is located in the X inactivation centre and belongs to a class of RNA molecules known as non-coding transcripts. ${ }^{19}$ With the exception of $3-15 \%, 1,500$ genes located on the human X chromosome undergo transcriptional silencing due to $\mathrm{X}$ inactivation. ${ }^{6}$

\section{Distinct X Chromosome Perturbations in Malignancy}

The differentiation status of cells is determined by $\mathrm{X}$ chromosome activity, whereby undifferentiated or poorly differentiated cells have been ascribed to the presence of two $\mathrm{Xa} .{ }^{20}$ Variations in Xi frequency have been reported with age, pregnancy, the use of oral contraceptives, fluctuations in menstrual cycle and neoplasia. ${ }^{21-25}$ Moore et al. found that the frequency of the sex chromatin in the nuclei of female hosts was low in malignant tissues, appearing in only about one-third of tumours in comparison to non-malignant tissues; this finding was attributed to the diverse chromosomal abnormalities that occur in malignancy. ${ }^{26}$ Straub et al . suggested that there was apparent reversion to the early embryonic state and loss of the Barr body in some female mammalian tumours wherein the condensed $\mathrm{X}$ chromosome may become partially or fully extended, altering its genetic activity. ${ }^{27}$ Thus, $\mathrm{X}$ chromosomes could be considered as existing in a dynamic state rather than a permanent or invariant one. ${ }^{28}$ It therefore appears that cancer is linked to an unusual escape from $\mathrm{X}$ inactivation. However, the extent of Xi perturbations and disruptions to the epigenetic state in cancer have not yet been systematically explored. Barring head and neck cancers, there is no dearth of literature reporting Xi reactivation in malignant tumours. ${ }^{29}$

Sirchia et al. noted that the lack of $\mathrm{X}$ inactivation in breast oncogenesis occurs independently from breast cancer 1 gene status and XIST expression and is due to the loss of the $\mathrm{Xi}$ and replication of the $\mathrm{Xa}$, without the reactivation of the native $\mathrm{Xi}$ (i.e. the $\mathrm{X}$ chromosome predestined to be inactivated from the beginning), which results in the gain of an additional Xa together with the lack of an Xi. ${ }^{18}$ According to Kaur et al., Barr body frequency in buccal mucosal cells was significantly lower among menstruating patients with cervical cancer as compared to those who were 


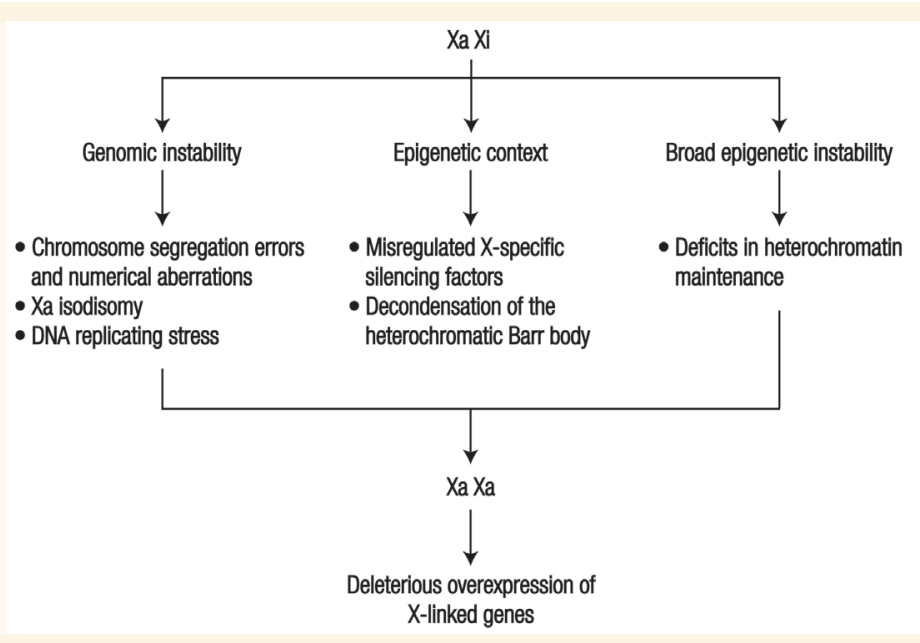

Figure 1: Possible mechanisms of $\mathrm{X}$ chromosome perturbations leading to the altered expression of $\mathrm{X}$-linked genes in malignancy.

$X a$ active $X$ chromosome; $X i=$ inactive $X$ chromosome

cancer-free; however, the findings were non-significant among breast cancer patients. ${ }^{30}$ This suggests that low Barr body frequency occurs only in the tissue directly involved with the change. In breast cancer patients, a significantly low incidence of inactive $\mathrm{X}$ chromatins has been observed among menstruating as well as menopausal women, indicating that this low incidence is due to $\mathrm{Xi}$ reactivation. ${ }^{21}$

Jäger et al. observed that DNA replication stress during oncogenesis led to $\mathrm{Xi}$ hypermutations in aberrantly proliferating cells; moreover, mutation rates were comparatively higher in late replicating regions due to the lack of transcription-coupled DNA repair. ${ }^{31}$ Furthermore, Vijay Kumar et al. reported a significant association between sex chromatin status and the histopathological grading of breast carcinomas, in which there was a lower frequency of sex chromatins in tumours with a higher microscopic grade. ${ }^{32}$ Another study found increased expression of cancer/testis antigens and loss of X inactivation in endometrial carcinoma cases which was attributed to global hypomethylation and a high number of copy number variations $(\mathrm{CNVs}){ }^{33}$ this might indicate that other cancers with a high degree of $\mathrm{CNV}$, such as colorectal cancer, nonsmall-cell lung cancer and HNSCC could also present with loss of X inactivation. Moreover, Kobayashi et al. reported that XIST expression could be used to predict the survival rate and prognosis of patients with cervical squamous cell carcinoma. ${ }^{11}$

Overall chromatin state is determined by DNA and histone modifications which maintain whether genes are transcriptionally active or inactive., ${ }^{2,3}$ The structure and function of chromatins and subsequent $\mathrm{X}$ inactivation can potentially become disrupted by environmental, toxicological and/or disease conditions; for example, recent research has indicated that XIST function may be severely affected by defects in heterochromatin stability and epigenetic modifications. ${ }^{34,35}$ The misexpression of XIST may potentially be a mechanism underlying oncogenesis and low XIST levels may reduce $\mathrm{X}$ inactivation with continuous $\mathrm{X}$ reactivation. ${ }^{20}$ However, the molecular cascade that alters $\mathrm{X}$ inactivation and $\mathrm{X}$ chromosome copy numbers in both female and male cancer cells remains undetermined. ${ }^{14}$ Several plausible explanations for Xi reactivation are proposed in Figure 1. Weakley et al. described three patterns of Xi loss in that certain cells lose Xi without Xa, others lose Xi and undergo $\mathrm{Xa}$ multiplication and a few undergo Xi reactivation. ${ }^{4}$ Significant epigenetic changes could also be caused by viral oncoproteins, which potentially lead to abnormal cellular growth, transformation and, in some cases, oncogenesis. ${ }^{36,37}$ Thus, virus-mediated transformation could be another explanation which has yet to be completely understood.

\section{X-Linked Genes in Head and Neck Squamous Cell Carcinoma}

The role of various $\mathrm{X}$-linked genes in different cancers has been previously documented. ${ }^{14}$ Consistent genetic abnormalities have been found to be associated with the development and/or progression of HNSCC in various karyotyping and molecular analyses. ${ }^{38}$ Martin et al. previously published a thorough description of specific genetic changes involving autosomes in oral squamous cell carcinoma cases, which included the loss of chromosomal segments 3p, 5q, 7q, 8p, 9p, 11q and $18 q$ in addition to the gain of $3 q, 5 p, 7 p, 8 q$ and $11 q$ 
Table 1: X-linked genes involved in the development of head and neck squamous cell carcinoma and other malignancies ${ }^{8,37,41-65}$

\section{Gene}

FHL1 Type

TSG

Function

Regulates muscle development, structural maintenance and signalling

TSGs

Potential regulators of the cell

$B E X$ genes

(including

$B E X 1, B E X 2$

$B E X 3, B E X 4$

and BEX5)

FOXP3

ATRX

MECP2

$D D X 3 X^{*}$

MAGE genes

$50,51,52$

and 53
Oncogene

TSG

Oncogenes

$$
\begin{aligned}
& \text { Encode certain tumour- } \\
& \text { associated antigens } \\
& \text { recognised by cytotoxic } \mathrm{T} \\
& \text { lymphocytes }
\end{aligned}
$$

Acts as a transcriptional activator, likely by binding to another epigenetic DNA modifier, and induces the MAPK and PI3K growth factor signalling pathways

Implicated in cell cycle regulation, cell and apoptosis

lymphoc)

Potentially involved in cell growth and development

\section{Locus \\ Role in HNSCC and other malignancies}

$\mathrm{Xq} 26$

- FHL1 mRNA and protein expression are frequently decreased in HNSCC cases, with FHL1 modulating HNSCC proliferation via the dysregulated expression of cyclin D1, cyclin E1 and p27.41

- FHL1 silencing notably enhances the proliferation of HNSCC cells, whereas forced FHL1 expression dramatically represses HNSCC cell growth. ${ }^{41}$

- The DNA hypermethylation of $F H L 1$ has been detected in certain types of cancer. ${ }^{41}$

Xq22 $\quad$ BEX4 controls OSCC proliferation and growth. ${ }^{42}$ - Reduced BEX4 expression occurs early on in OSCC development. ${ }^{42}$

- $B E X$ genes are epigenetically silenced in OSCC cases. ${ }^{43}$ - BEX1 and BEX3 are involved in modulating the NF- $\mathrm{kB}$ signalling pathway and have been implicated in cell death and the cell cycle. ${ }^{44}$

Xp11.23 - The FOXP3 gene modulates the expression of various other genes implicated in cancer development (i.e. TSGs and oncogenes). ${ }^{45}$

- Immune evasion via FOXP3 expression in tumour cells may represent the main mechanism of cancer progression. ${ }^{45}$ - High FOXP3 expression in tumours has been found to be significantly associated with poor prognosis in OSCC cases (e.g. decreased survival and lymph node metastasis). ${ }^{46}$

Xq21.1 - ATRX is one of the most frequently mutated chromatin factors in cancers. ${ }^{45}$

- ATRX mutations promote telomere lengthening, increased genomic instability and cellular proliferation. ${ }^{45}$

- ATRX loss-of-function mutations have been associated with cancers that exhibit ALT phenotypes, including oesophageal SCC. ${ }^{47}$

- ATRX mutations have also been associated with abnormal DNA methylation patterns. ${ }^{47}$

Xq28 - MECP2 amplification/overexpression has been linked to cancer. ${ }^{48}$

Xp11.4 - DDX3X expression has been evaluated in breast, lung, colon, oral and liver cancers and a positive correlation has been recently reported between high $D D X 3 X$ levels and poor prognosis in human tumours. ${ }^{49}$

- DDX3X inhibits apoptosis by reducing caspase 3 activation. ${ }^{49}$ - An inverse relation between cytoplasmic $D D X 3 X$ expression and survival rate has been found in smokers with OSCC.49 - Missense DDX3X mutations have been reported in HNSCC and HPV patients. ${ }^{49}$

Xq26-28 - Several MAGEA subgroups contribute to malignancy. $\mathrm{Xp}^{\dagger} 1^{\dagger}$ - One study found that $71 \%$ of HNSCC cases expressed at least one of six different $M A G E$ genes..$^{50}$ - MAGE1 and MAGE4 were the most frequently expressed genes in poorly differentiated SCC cases. ${ }^{50}$

- The transcription of $M A G E$ genes may be linked to a transformation event; various viruses (such as HPV and EBV) have easy access to the head and neck region, which might influence cell transformation. ${ }^{51}$

- In HNSCC cases, MAGEA2 expression is regulated by promoter demethylation, which interacts with the p53 pathway by increasing cellular proliferation and decreasing cell cycle arrest..$^{52}$

- As a result of promoter demethylation, MAGEB2 overexpression was reported almost exclusively in tumours, with growth-promoting effects. ${ }^{53}$

Xp11.3 - ARAF1 may be involved in malignancy as a component gene of the MAPK pathway. ${ }^{54}$ 


\begin{tabular}{|c|c|c|}
\hline$F A N C B$ & TSG & Involved in DNA repair \\
\hline $\begin{array}{l}\text { COL } 4 A 6 \text { and } \\
\text { COL4A5 } \\
\text { genes }\end{array}$ & $\begin{array}{l}\text { Collagen } \\
\text { genes }\end{array}$ & $\begin{array}{l}\text { Involved in synthesising } \\
\text { COL4, an important } \\
\text { protective component against } \\
\text { invasion and metastasis }\end{array}$ \\
\hline$E L K 1^{\ddagger}$ & $\begin{array}{l}\text { Transcription } \\
\text { activator gene }\end{array}$ & $\begin{array}{l}\text { Involved in determining } \\
\text { the cellular response to } \\
\text { extracellular signals and } \\
\text { controlling the expression of } \\
\text { genes involved in cell cycle } \\
\text { progression, differentiation } \\
\text { and apoptosis }\end{array}$ \\
\hline$G 6 P D$ & Oncogene & $\begin{array}{l}\text { Encodes the G6PD enzyme } \\
\text { which produces NADPH } \\
\text { and pentoses involved in } \\
\text { reductive biosynthetic } \\
\text { activity }\end{array}$ \\
\hline$L D O C 1$ & TSG & $\begin{array}{l}\text { Able to induce apoptosis } \\
\text { in various kinds of human } \\
\text { cancer cells }\end{array}$ \\
\hline SSX genes & Oncogenes & $\begin{array}{l}\text { Expression of these genes } \\
\text { is restricted to malignant } \\
\text { tumours }\end{array}$ \\
\hline XIAP & Oncogene & $\begin{array}{l}\text { Encodes a protein that } \\
\text { belongs to a family of } \\
\text { apoptotic suppressor } \\
\text { proteins/caspase inhibitors }\end{array}$ \\
\hline $\begin{array}{l}K D M 6 A \\
\text { and } K D M 6 B \\
\text { genes }\end{array}$ & TSGs & $\begin{array}{l}\text { Act as the only enzymes } \\
\text { displaying histone di- and tri- } \\
\text { demethylase activity and are } \\
\text { required for the reactivation } \\
\text { of epigenetically silenced } \\
\text { genes }\end{array}$ \\
\hline $\begin{array}{l}\text { APEX2 and } \\
\text { TREX2 genes }\end{array}$ & $\begin{array}{l}\text { DNA repair } \\
\text { genes }\end{array}$ & DNA repair \\
\hline
\end{tabular}

Xp22.2 Patients with Fanconi's anaemia have been reported to have an increased susceptibility to early-onset HNSCC. ${ }^{55}$ - FANCB hypermethylation has been observed sporadically in HNSCC tumours. ${ }^{55}$

Xq22 - In carcinogenesis, COL4 is gradually fragmented, collapsed or even dissolved completely, thus providing channels for cancer cells to invade the lamina propria..$^{56}$

- As they become less differentiated, SCC cells were found to lose their ability to form basement membrane components. ${ }^{56}$

Xp11.23 ELK1 proteins are a nuclear target for the Ras-Raf-MAPK signalling cascade which is important for the control of growth signals, differentiation and cell survival. ${ }^{57}$

- ELK1 is involved in the hypoxic induction of HIF2 $\alpha$ dependent genes, which can facilitate tumour cell survival by making them more resistant to therapeutic intervention. ${ }^{58}$

Xq28 - Increased G6PD activity has been found in cancer cells..$^{59}$ - G6PD inhibition has been reported to decrease cancer cell survival and NADPH levels and increase ROS production..$^{59}$ - Some researchers consider high G6PD activity to be an independent negative prognostic marker in cancer. ${ }^{60}$ - In breast cancer patients, G6PD overexpression is considered a predictor of high risk of recurrent metastasis. ${ }^{61}$ - G6PD becomes hyperactive in tumours with p53 inactivation, such as HNSCC. ${ }^{60}$

- G6PD activity ensures a steady supply of pentoses and stabilisation of the NADPH equilibrium which is an essential prerequisite for uncontrolled cell growth and proliferation, particularly for tumour cells. ${ }^{61}$

Xq27 - LDOC1 downregulation due to epigenetic silencing by promoter hypermethylation has been observed in oral, cervical and ovarian cancers. ${ }^{43}$

Xp11.1-11.2 • Expression of at least one SSX subfamily member was most frequently observed in head and neck cancer (75\%), followed by ovarian cancer (50\%), malignant melanomas (43\%), lymphomas (36\%), colorectal cancer (27\%) and breast cancer $(23 \%)^{62}$

Xq25 - The elevated expression of potent apoptotic inhibitor XIAP is a significant biomarker for HNSCC, with high XIAP expression predicting poor prognosis. ${ }^{63}$

- XIAP overexpression in tumour cells has been shown to inhibit cell death induced by a variety of apoptotic stimuli and induce resistance to chemotherapy. ${ }^{63}$

- The XIAP gene was found to be hypomethylated in oral tumours. ${ }^{63}$

Xp11.3 $\quad$ HPV type 16 E7 expression has been reported to cause $K D M 6 A$ and $K D M 6 B$ upregulation, resulting in epigenetic reprogramming as evidenced by the aberrant expression of homeobox genes which are frequently dysregulated during carcinogenesis. ${ }^{37,64}$

- These genes have been found to be mutated in $>10 \%$ of HNSCC cell lines, although not in human HNSCC tumours. ${ }^{65}$

Xp11.21
- APEX2 and TREX2 genes are hypomethylated in cancer tissues. ${ }^{8}$

- Screening suggests DNA repair genes, which are located on the $\mathrm{X}$ chromosome, have a propensity for aberrant methylation. ${ }^{8}$

FHL1 = four-and-a-halfLIM domains; TSG = tumour suppressor gene; $m$ RNA = messenger ribonucleic acid; HNSCC = head and neck and squamous cell carcinoma; $B E X=$ brain-expressed $X$-linked; OSCC = oral squamous cell carcinoma; $N F-\kappa B=$ nuclear factor kappa $B ; F O X P 3=$ forkhead box P3; $A T R X=\alpha$-thalassemia mental retardation syndrome, $X$-linked; $A L T$ = alternative lengthening of telomeres; $S C C=$ squamous cell carcinoma; $M E C P 2=$ methyl cytosine guanine dinucleotide-binding protein 2; MAPK = mitogen-activated protein kinase; PI3K = phosphoinositide 3-kinase; DDX3X = DEAD-box helicase 3, X-linked; HPV = human papillomavirus; $M A G E=$ melanoma-associated antigen; EBV = Epstein-barr virus; $A R A F 1=A$-Raf proto-oncogene, serine/threonine kinase; FANCB = Fanconi's anaemia complementation group B; COL4 = collagen type IV; ELK1 = E26 transformation-specific domain-containing protein Elk-1; HIF2 $\alpha=$ hypoxia-inducible factor $2 \alpha ;$ G6PD = glucose-6-phosphate dehydrogenase; NADPH = nicotinamide adenine dinucleotide phosphate; ROS = reactive oxygen species; LDOC1 = leucine zipper downregulated in cancer 1; SSX = synovial sarcoma, X chromosome-related; XIAP = X-linked inhibitor of apoptosis; KDM6 = lysine-specific demethylase 6; APEX2 = apurinic/ apyrimidinic endodeoxyribonuclease 2; TREX2 = three prime repair exonuclease 2.

*DDX3X is a highly conserved subfamily of DEAD-box proteins, the largest group of RNA helicases. ${ }^{\dagger}$ Type I MAGE genes in the MAGEA, MAGEB and MAGEC subfamilies are clustered on chromosome X. Type II MAGE genes in the MAGED, MAGEE, MAGEF, MAGEH, MAGEL and necdin-like protein subfamilies are clustered on chromosome $X$ as well as a few autosomes. ${ }^{\neq} A$ member of the E26 transformation-specific oncogene family. ${ }^{\circledR} N F-k B$ regulates vascular endothelial growth factor expression through ELK1 and activator protein 1 transcription factors. $9 S X$ genes comprise six members of the recently described cancer/testis antigen class. 
Table 2: Hypothesised mechanisms leading to X reactivation in the development of head and neck squamous cell carcinoma ${ }^{3,5-7,14,66}$

Mechanism
Loss of Xi via deletion
Chromosomal segregation errors
Reactivation of Xi through epigenetic changes (i.e. hypo-
methylation or heterochromatin instability)
HPV oncoproteins influencing XIST expression
DNA replicating stress in proliferating malignant cells
Translocations involving regions of the X chromosome to
autosomes and vice versa
HPV = human papilloma virus; $X i=$ inactive $X$ chromosome;
$X I S T=$ X-inactive specific transcript.

segments. ${ }^{39}$ However, a sex link was dubious; the loss of the short arm of the Xi was a common observation in females and Y loss was observed in about 50\% of males. ${ }^{39}$

In HNSCC cases, Xi reactivation can potentially be considered a marker of heterochromatin instability associated with poor prognosis as, much like cervical cancer, the disease may be associated with epigenetic modifications as well as oncoviruses that could alter the X-linked genes. ${ }^{11,36,37}$ Thus, the destabilised genomic repertoire in HNSCC appears to be further undermined by epigenetic events. ${ }^{39,40}$ However, before considering an association between the Barr body and HNSCC, a causal relation between X-linked TSGs and HNSCC development must be established. A summary of the X-linked genes involved in HNSCC development and their various loci, functions and mechanisms can be found in Table 1.8,37,41-65 The involvement of X-linked genes in HNSCC, which bears similarities to the molecular pathogenesis of cervical carcinomas and other epithelial malignancies, indicate that there is a potential association between altered Barr body frequency and HNSCC development. Probable contributors leading to $\mathrm{Xi}$ reactivation in HNSCC cases are documented in Table 2.3,5-7,14,66 However, these hypothetical conclusions can only be confirmed or negated by experimental research.

Major disruptions in the DNA methylation profiles of malignant cells-including the hypermethylation of gene promoters, global hypomethylation and increased mutation rates at methylated CpG dinucleotides-have been observed in both HPV-positive and -negative patients with HNSCC. ${ }^{67}$ Additionally, Fang et al. found that individual genes and gene expression programmes are regulated by various long non-coding RNAs by either implicating epigenetic control or altering basal transcriptional machinery. ${ }^{68}$ According to Goedert et al., long non-coding RNAs induced by viral oncoproteins play critical roles in tumour initiation and progression. ${ }^{69}$ As previously mentioned, increased XIST expression-which contains a long non-coding RNA transcript-has been found to predict a favourable prognosis in cases of cervical squamous cell carcinoma. ${ }^{11}$ Since the transcriptional capacity of host cell chromatins can be regulated by HPV E6 and E7 oncoproteins, further research is needed to fully comprehend HPV-induced modulation of long non-coding RNAs. ${ }^{70}$

\section{Clinical Implications}

$\mathrm{Xi}$ reactivation is an emerging topic of interest with potential clinically relevant applications which may pave the way for further understanding of chromatin changes and other drivers of tumour development. $\mathrm{X}$-linked genes can serve as potential targets for the genetic and epigenetic alterations observed in malignant cells. Therefore, considering heterochromatin defects and the involvement of epigenetic processes in switching on or off transcriptional cell machinery in malignancy, attempts have been made to delineate specific drug targets. ${ }^{71}$ Epimutations could potentially be reversed via chemical agents known as epidrugs, such as DNA methyltransferase or histone deacetylase inhibitors which help to re-establish the expression of tumour suppressors that have been suppressed by hypermethylation or repressive chromatin marks. ${ }^{72}$ The upregulation of oncogenes and cancer/testis antigens located on the X chromosome are induced by the loss of $\mathrm{X}$ inactivation, which leads to increased tumour aggressiveness; this could therefore be a susceptible target for immunotherapy. ${ }^{73}$ Other options for reactivating X-linked TSGs in cancer therapy also deserve further investigation. ${ }^{4}$ Advanced genomic techniques, single-cell profiling and other highly specific tools could be utilised to explore epigenetic changes and $\mathrm{X}$ inactivation, thus opening new horizons for HNSCC treatment. ${ }^{74}$

\section{Conclusion}

Previous research has elucidated in detail the physiological phenomenon of $\mathrm{X}$ inactivation and subsequent reactivation in various malignancies, particularly breast, ovarian and cervical cancers in females. This article reviewed the distinct perturbations of the $\mathrm{X}$ chromosome in various malignancies and suggested a similar hypothesis for HNSCC development. The careful profiling of X-linked gene expression in tumour cells could help to elucidate the $\mathrm{X}$ chromosome-related events which lead to oncogenesis. 


\section{References}

1. Herceg Z, Hainaut P. Genetic and epigenetic alterations as biomarkers for cancer detection, diagnosis and prognosis. Mol Oncol 2007; 1:26-41. doi: 10.1016/j.molonc.2007.01.004.

2. Clark SJ. Action at a distance: Epigenetic silencing of large chromosomal regions in carcinogenesis. Hum Mol Genet 2007; 16:R88-95. doi: 10.1093/hmg/ddm051.

3. Weakley SM, Wang H, Yao Q, Chen C. Expression and function of a large non-coding RNA gene XIST in human cancer. World J Surg 2011; 35:1751-6. doi: 10.1007/s00268-010-0951-0.

4. Liu Y, Wang L, Zheng P. X-linked tumor suppressors: Perplexing inheritance, a unique therapeutic opportunity. Trends Genet 2010; 26:260-5. doi: 10.1016/j.tig.2010.03.004

5. Carone DM, Lawrence JB. Heterochromatin instability in cancer: From the Barr body to satellites and the nuclear periphery. Semin Cancer Biol 2013; 23:99-108. doi: 10.1016/j. semcancer.2012.06.008.

6. Chaligné R, Popova T, Mendoza-Parra MA, Saleem MA Gentien D, Ban K, et al. The inactive X chromosome is epigenetically unstable and transcriptionally labile in breast cancer. Genome Res 2015; 25:488-503. doi: 10.1101/gr.18 5926.114

7. Pageau GJ, Hall LL, Ganesan S, Livingston DM, Lawrence JB. The disappearing Barr body in breast and ovarian cancers. Nat Rev Cancer 2007; 7:628-33. doi: 10.1038/nrc2172.

8. Chaisaingmongkol J, Popanda O, Warta R, Dyckhoff G, Herpel E, Geiselhart L, et al. Epigenetic screen of human DNA repair genes identifies aberrant promoter methylation of NEIL1 in head and neck squamous cell carcinoma. Oncogene 2012; 31:5108-16. doi: 10.1038 /onc. 2011.660.

9. Koffler J, Sharma S, Hess J. Predictive value of epigenetic alterations in head and neck squamous cell carcinoma. Mol Cell Oncol 2014; 1:e954827. doi: 10.1080/23723548.2014.954827.

10. Bakhtiar SM, Ali A, Barh D. Epigenetics in head and neck cancer. Methods Mol Biol 2015; 1238:751-69. doi: 10.1007/9781-4939-1804-1_39.

11. Kobayashi R, Miyagawa R, Yamashita H, Morikawa T, Okuma K, Fukayama $\mathrm{M}$, et al. Increased expression of long non-coding RNA XIST predicts favorable prognosis of cervical squamous cell carcinoma subsequent to definitive chemoradiation therapy. Oncol Lett 2016; 12:3066-74. doi: 10.3892/ol.2016.5054.

12. Jiang F, Richter J, Schraml P, Bubendorf L, Gasser T, Sauter G, et al. Chromosomal imbalances in papillary renal cell carcinoma: Genetic differences between histological subtypes. Am J Pathol 1998; 153:1467-73. doi: 10.1016/S0002-9440(10)65734-3.

13. Sadikovic B, Al-Romaih K, Squire JA, Zielenska M. Cause and consequences of genetic and epigenetic alterations in human cancer. Curr Genomics 2008; 9:394-408. doi: 10.2174/ 138920208785699580

14. Spatz A, Borg C, Feunteun J. X-chromosome genetics and human cancer. Nat Rev Cancer 2004; 4:617-29. doi: 10.1038/ nrc1413.

15. Hysolli E, Jung YW, Tanaka Y, Kim KY, Park IH. The lesser known story of $\mathrm{X}$ chromosome reactivation: A closer look into the reprogramming of the inactive $\mathrm{X}$ chromosome. Cell Cycle 2012; 11:229-35. doi: 10.4161/cc.11.2.18998.

16. Barr ML, Bertram EG. A morphological distinction between neurones of the male and female, and the behaviour of the nucleolar satellite during accelerated nucleoprotein synthesis. Nature 1949; 163:676. doi: 10.1038/163676a0.

17. Chow JC, Yen Z, Ziesche SM, Brown CJ. Silencing of the mammalian X chromosome. Annu Rev Genomics Hum Genet 2005; 6:69-92. doi: 10.1146/annurev.genom.6.080604.162350.

18. Sirchia SM, Ramoscelli L, Grati FR, Barbera F, Coradini D, Rossella F, et al. Loss of the inactive $\mathrm{X}$ chromosome and replication of the active $\mathrm{X}$ in BRCA1-defective and wildtype breast cancer cells. Cancer Res 2005; 65:2139-46. doi: 10.1158/0008-5472.CAN-04-3465.
19. Kalantry S. Recent advances in X-chromosome inactivation. J Cell Physiol 2011; 226:1714-18. doi: 10.1002/jcp.22673.

20. Vallot C, Ouimette JF, Rougeulle C. Establishment of X chromosome inactivation and epigenomic features of the inactive X depend on cellular contexts. Bioessays 2016; 38:869-80. doi: 10.1002/bies.201600121.

21. Natekar PE, Desouza FM. Reactivation of inactive $\mathrm{X}$ chromosome in buccal smear of carcinoma of breast. Indian J Hum Genet 2008; 14:7-8. doi: 10.4103/0971-6866.42320.

22. Chhabra V, Siddiqui MS, Singh U, Srivastava AN, Sahai A, Sharma PK. Sex chromatin \& primary amenorrhoea: A correlation study. J Anat Soc India 2002; 51:145-7.

23. Ghosh SN, Shah PN. Probable mechanism for the loss of Barr body in human female tumor with special reference to breast cancer. Med Hypotheses 1981; 7:1099-104. doi: 10.1016/03069877(81)90106-7.

24. Fischer $\mathrm{AH}$, Zhao $\mathrm{C}$, Li QK, Gustafson KS, Eltoum IE, Tambouret R, et al. The cytologic criteria of malignancy. J Cell Biochem 2010; 110:795-811. doi: 10.1002/jcb.22585.

25. Ørstavik KH. Skewed X inactivation in healthy individuals and in different diseases. Acta Paediatr Suppl 2006; 95:24-9. doi: $10.1080 / 08035320600618783$

26. Moore KL, Barr ML. The sex chromatin in human malignant tissues. Br J Cancer 1957; 11:384-90.

27. Straub DG, Lucas LA, McMahon NJ, Pellett OL, Teplitz RL. Apparent reversal of X-condensation mechanism in tumors of the female. Cancer Res 1969; 29:1233-43.

28. Brown CJ. Role of the X chromosome in cancer. J Natl Cancer Inst 1996; 88:480-2. doi: 10.1093/jnci/88.8.480.

29. Deng X, Berletch JB, Nguyen DK, Disteche CM. X chromosome regulation: Diverse patterns in development, tissues and disease. Nat Rev Genet 2014; 15:367-78. doi: 10.1038/nrg3687.

30. Kaur S, Sambyal V, Sharma A, Kaur P. Buccal mucosal $\mathrm{X}$-chromatin frequency in breast and cervix cancer. Anthropol 2006, 8:223-5.

31. Jäger N, Schlesner M, Jones DT, Raffel S, Mallm JP, Junge KM, et al. Hypermutation of the inactive $\mathrm{X}$ chromosome is a frequent event in cancer. Cell 2013; 155:567-81. doi: 10.1016/j. cell.2013.09.042.

32. Vijay Kumar B, Ravneet K, Manjit Singh B, Ranjeev B, Kalyan GS, Nishit G, et al. Correlation between sex chromatin and female breast tumour in paraffin sections, buccal smears and peripheral blood films. J Clin Diagn Res 2014; 8:92-5. doi: $10.7860 / J C D R / 2014 / 8289.4117$

33. Kang J, Lee HJ, Jun SY, Park ES, Maeng LS. Cancer-testis antigen expression in serous endometrial cancer with loss of X chromosome inactivation. PLoS One 2015; 10:e0137476. doi: 10.1371/journal.pone.0137476.

34. De La Fuente R, Baumann C, Viveiros MM. Role of ATRX in chromatin structure and function: Implications for chromosome instability and human disease. Reproduction 2011; 142:221-34. doi: 10.1530/REP-10-0380.

35. Cerase A, Pintacuda G, Tattermusch A, Avner P. Xist localization and function: New insights from multiple levels. Genome Biol 2015; 16:166. doi: 10.1186/s13059-015-0733-y.

36. Kawakami T, Zhang C, Taniguchi T, Kim CJ, Okada Y, Sugihara H, et al. Characterization of loss-of-inactive $\mathrm{X}$ in Klinefelter syndrome and female-derived cancer cells. Oncogene 2004; 23:6163-9. doi: 10.1038/sj.onc.1207808

37. McLaughlin-Drubin ME, Crum CP, Münger K. Human papillomavirus E7 oncoprotein induces KDM6A and KDM6B histone demethylase expression and causes epigenetic reprogramming. Proc Natl Acad Sci U S A 2011; 108:2130-5. doi: 10.10 73/pnas.1009933108

38. Veiga LC , Bérgamo NA, Kowalski LP, Rogatto SR. Classical and molecular cytogenetic analysis in head and neck squamous cell carcinomas. Genet Mol Biol 2003; 26:121-28. doi: 10.1590/ S1415-47572003000200003. 
39. Martin CL, Reshmi SC, Ried T, Gottberg W, Wilson JW, Reddy JK, et al. Chromosomal imbalances in oral squamous cell carcinoma: Examination of 31 cell lines and review of the literature. Oral Oncol 2008; 44:369-82. doi: 10.1016/j. oraloncology.2007.05.003.

40. Brown CJ, Carrel L, Willard HF. Expression of genes from the human active and inactive X chromosomes. Am J Hum Genet 1997; 60:1333-43. doi: 10.1086/515488.

41. Cao W, Liu J, Xia R, Lin L, Wang X, Xiao M, et al. X-linked FHL1 as a novel therapeutic target for head and neck squamous cell carcinoma. Oncotarget 2016; 7:14537-50. doi: 10.18632/ oncotarget.7478.

42. Gao W, Li JZ, Chen SQ, Chu CY, Chan JY, Wong TS. Decreased brain-expressed X-linked 4 (BEX4) expression promotes growth of oral squamous cell carcinoma. J Exp Clin Cancer Res 2016; 35:92. doi: 10.1186/s13046-016-0355-6.

43. Lee CH, Wong TS, Chan JY, Lu SC, Lin P, Cheng AJ, et al. Epigenetic regulation of the X-linked tumour suppressors BEX1 and LDOC1 in oral squamous cell carcinoma. J Pathol 2013; 230:298-309. doi: 10.1002/path.4173.

44. Fernandez EM, Díaz-Ceso MD, Vilar M. Brain expressed and X-linked (Bex) proteins are intrinsically disordered proteins (IDPs) and form new signaling hubs. PLoS One 2015; 10:e0117206. doi: 10.1371/journal.pone.0117206.

45. Liu $\mathrm{R}$, Kain $\mathrm{M}$, Wang L. Inactivation of X-linked tumor suppressor genes in human cancer. Future Oncol 2012; 8:463-81. doi: $10.2217 /$ fon. 12.26 .

46. Song JJ, Zhao SJ, Fang J, Ma D, Liu XQ, Chen XB, et al. Foxp3 overexpression in tumor cells predicts poor survival in oral squamous cell carcinoma. BMC Cancer 2016; 16:530. doi: 10. 1186/s12885-016-2419-6.

47. Watson LA, Goldberg H, Bérubé NG. Emerging roles of ATRX in cancer. Epigenomics 2015; 7:1365-78. doi: 10.2217/epi.15.82.

48. Neupane M, Clark AP, Landini S, Birkbak NJ, Eklund AC, Lim E, et al. MECP2 is a frequently amplified oncogene with a novel epigenetic mechanism that mimics the role of activated RAS in malignancy. Cancer Discov 2016; 6:45-58. doi: 10.11 58/2159-8290.CD-15-0341.

49. Bol GM, Xie M, Raman V. DDX3, a potential target for cancer treatment. Mol Cancer 2015; 14:188. doi: 10.1186/s12943-0150461-7.

50. Eura M, Ogi K, Chikamatsu K, Lee KD, Nakano K, Masuyama K, et al. Expression of the MAGE gene family in human head-andneck squamous-cell carcinomas. Int J Cancer 1995; 64:304-8. doi: $10.1002 /$ ijc. 2910640504 .

51. Zakut R, Topalian SL, Kawakami Y, Mancini M, Eliyahu S, Rosenberg SA. Differential expression of MAGE-1, -2 and -3 messenger RNA in transformed and normal human cell lines. Cancer Res 1993; 53:5-8.

52. Glazer CA, Smith IM, Bhan S, Sun W, Chang SS, Pattani KM, et al. The role of MAGEA2 in head and neck cancer. Arch Otolaryngol Head Neck Surg 2011; 137:286-93. doi: 10.1001/ archoto.2011.2.

53. Peche LY, Ladelfa MF, Toledo MF, Mano M, Laiseca JE, Schneider C, et al. Human MAGEB2 expression enhances E2F activity, cell proliferation and resistance to ribotoxic stress. J Biol Chem 2015; 290:29652-62. doi: 10.1074/jbc.M115.671982.

54. Rauch J, Vandamme D, Mack B, McCann B, Volinsky N, Blanco A, et al. Differential localization of A-Raf regulates MST2-mediated apoptosis during epithelial differentiation. Cell Death Differ 2016; 23:1283-95. doi: 10.1038/cdd.2016.2.

55. Smith IM, Mithani SK, Mydlarz WK, Chang SS, Califano JA. Inactivation of the tumor suppressor genes causing the hereditary syndromes predisposing to head and neck cancer via promoter hypermethylation in sporadic head and neck cancers. ORL J Otorhinolaryngol Relat Spec 2010; 72:44-50. doi: $10.1159 / 000292104$
56. Gouse S, Girish HC, Sangamad R. Role of type IV collagen in oral squamous cell carcinoma. Res J Pharm Biol Chem Sci 2016; 7:2737-41

57. Roberts PJ, Der CJ. Targeting the Raf-MEK-ERK mitogenactivated protein kinase cascade for the treatment of cancer. Oncogene 2007; 26:3291-310. doi: 10.1038/sj.onc.1210422.

58. Salnikow K, Aprelikova O, Ivanov S, Tackett S, Kaczmarek M, Karaczyn A, et al. Regulation of hypoxia-inducible genes by ETS1 transcription factor. Carcinogenesis 2008; 29:1493-9. doi: 10.1093/carcin/bgn088.

59. Hu T, Li YS, Chen B, Chang YF, Liu GC, Hong Y, et al. Elevated glucose-6-phosphate dehydrogenase expression in the cervical cancer cases is associated with the cancerigenic event of highrisk human papillomaviruses. Exp Biol Med (Maywood) 2015; 240:1287-97. doi: 10.1177/1535370214565971.

60. Jiang P, Du W, Wu M. Regulation of the pentose phosphate pathway in cancer. Protein Cell 2014; 5:592-602. doi: 10.1007/ s13238-014-0082-8.

61. Cernaj IE. Simultaneous dual targeting of Par-4 and G6PD: A promising new approach in cancer therapy? Quintessence of a literature review on survival requirements of tumor cells. Cancer Cell Int 2016; 16:87. doi: 10.1186/s12935-016-0363-9.

62. Türe ci O, Chen YT, Sahin U, Güre AO, Zwick C, Villena C, et al. Expression of SSX genes in human tumors. Int $\mathrm{J}$ Cancer 1998; 77:19-23. doi: 10.1002/(SICI)1097-0215(199 80703)77:1<19::AID-IJC4>3.0.CO;2-2.

63. Yang HX, Liu L, Xu JH, Hu YJ, Zhang P, Qiu JX. Co-expression of XIAP and CIAP1 play synergistic effect on patient's prognosis in head and neck cancer. J Mol Biomark Diagn 2016; 8:314. doi: 10.4172/2155-9929.1000314.

64. Hyland PL, McDade SS, McCloskey R, Dickson GJ, Arthur K, McCance DI, et al. Evidence for alteration of EZH2, BMI1, and KDM6A and epigenetic reprogramming in human papillomavirus type 16 E6/E7-expressing keratinocytes. J Virol 2011; 85:10999-1006. doi: 10.1128/JVI.00160-11.

65. Li H, Wawrose JS, Gooding WE, Garraway LA, Lui VW, Peyser ND, et al. Genomic analysis of head and neck squamous cell carcinoma cell lines and human tumors: A rational approach to preclinical model selection. Mol Cancer Res 2014; 12:571-82. doi: 10.1158/1541-7786.MCR-13-0396.

66. Wang J. Method to analyze X-chromosomal genetic data. From: http:/grantome.com/grant/NIH/R03-CA192197-02 Accessed: Aug 2017.

67. Worsham MJ, Stephen JK, Chen KM, Havard S, Shah V, Gardner G, et al. Delineating an epigenetic continuum in head and neck cancer. Cancer Lett 2014; 342:178-84. doi: 10.1016/j. canlet.2012.02.018.

68. Fang Y, Fullwood MJ. Roles, functions, and mechanisms of long non-coding RNAs in cancer. Genomics Proteomics Bioinformatics 2016; 14:42-54. doi: 10.1016/j.gpb.2015.09.006.

69. Goedert L, Plaça JR, Nunes EM, Debom GN, Espreafico EM. Long noncoding RNAs in HPV-induced oncogenesis. Adv Tumor Virol 2016; 6:1-9. doi: 10.4137/ATv.s29816.

70. Plesa A, Iancu IV, Botezatu A, Huica I, Stoian M, Anton G. The involvement of epigenetic mechanisms in HPV-induced cervical cancer. In: Rajkumar R, Ed. Human Papillomavirus: Research in a global perspective. London, UK: InTechOpen, 2016. Pp. 191-239.

71. Mund C, Brueckner B, Lyko F. Reactivation of epigenetically silenced genes by DNA methyltransferase inhibitors: Basic concepts and clinical applications. Epigenetics 2006; 1:7-13. doi: 10.4161/epi.1.1.2375

72. Timp W, Feinberg AP. Cancer as a dysregulated epigenome allowing cellular growth advantage at the expense of the host. Nat Rev Cancer 2013; 13:497-510. doi: 10.1038/nrc3486. 
73. Kang J, Lee HJ, Kim J, Lee JJ, Maeng LS. Dysregulation of $\mathrm{X}$ chromosome inactivation in high grade ovarian serous adenocarcinoma. PLoS One 2015; 10:e0118927. doi: 10.1371/ journal.pone.0118927.
74. Agrelo R, Wutz A. ConteXt of change: $\mathrm{X}$ inactivation and disease. EMBO Mol Med 2010; 2:6-15. doi: 10.1002/ emmm.200900053. 